\title{
Retrieval of dust aerosols during night: improved assessment of long wave dust radiative forcing over Afro-Asian regions
}

\author{
S. Deepshikha ${ }^{1}$ and J. Srinivasan ${ }^{1,2}$ \\ ${ }^{1}$ Centre for Atmospheric and Oceanic Sciences, Indian Institute of Science, Bangalore-560012, India \\ ${ }^{2}$ Divecha Centre for Climate Change, Indian Institute of Science, Bangalore, India
}

Received: 13 July 2010 - Accepted: 5 August 2010 - Published: 18 August 2010

\begin{abstract}
Several investigators in the past have used the radiance depression (with respect to clear-sky infrared radiance), resulting from the presence of mineral dust aerosols in the atmosphere, as an index of dust aerosol load in the atmosphere during local noon. Here, we have used a modified approach to retrieve dust index during night since assessment of diurnal average infrared dust forcing essentially requires information on dust aerosols during night. For this purpose, we used infrared radiance $(10.5-12.5 \mu \mathrm{m})$, acquired from the METEOSAT-5 satellite ( $\sim 5 \mathrm{~km}$ resolution). We found that the "dust index" algorithm, valid for daytime, will no longer hold during the night because dust is then hotter than the theoretical dust-free reference. Hence we followed a "minimum reference" approach instead of a conventional "maximum reference" approach. A detailed analysis suggests that the maximum dust load occurs during the daytime. Over the desert regions of India and Africa, maximum change in dust load is as much as a factor of four between day and night and factor of two variations are commonly observed. By realizing the consequent impact on long wave dust forcing, sensitivity studies were carried out, which indicate that utilizing day time data for estimating the diurnally averaged long-wave dust radiative forcing results in significant errors (as much as 50 to $70 \%$ ). Annually and regionally averaged long wave dust radiative forcing (which account for the diurnal variation of dust) at the top of the atmosphere over Afro-Asian region is $2.6 \pm 1.8 \mathrm{~W} \mathrm{~m}^{-2}$, which is 30 to $50 \%$ lower than those reported earlier. Our studies indicate that neglecting diurnal variation of dust while assessing its radiative impact leads to an overestimation of dust radiative forcing, which in turn result in underestimation of the radiative impact of anthropogenic aerosols.
\end{abstract}

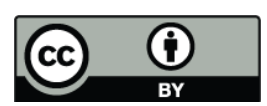

Correspondence to: S. Deepshikha (singh.deepshikha1@gmail.com)
Keywords. Atmospheric composition and structure (Aerosols and particles; Transmission and scattering of radiation) - History of geophysics (Atmospheric sciences)

\section{Introduction}

The desert aerosol can have a significant impact on the atmospheric radiation (Sokolik et al., 1998). Dust not only scatters but also absorbs solar radiation and also absorbs and emits long wave radiation (Haywood and Boucher, 2000). The magnitude and even the sign of direct radiative forcing by dust is uncertain due to lack of adequate data (IPCC, 2007). It depends on a number of parameters, such as the optical properties of dust, its vertical distribution, cloud cover and the albedo of the underlying surface (Liao and Seinfeld, 1998). There are some difficulties involved in remote sensing (using visible wavelengths) of dust over land due to high and varying albedo (Kaufman et al., 1997). In addition, dust aerosols are known to be non-spherical in shape. This can cause errors in the remote sensing of dust aerosols from visible wavelengths. Recent investigations as part of Aerosol Characterization Experiment-Asia (ACE-Asia) have shown that the dust we observe may not be just dust, but it may be dust mixed with other aerosols (Seinfeld et al., 2004). Dust particles mixed with soot, sulfates, nitrates or aqueous solutions can have drastically different properties from those at the dust source (Chandra et al., 2004; Deepshikha et al., 2005). Several investigators in the past have used the radiance depression (with respect to clear-sky infrared radiance), resulting from the presence of mineral dust aerosols in the atmosphere, as an index of dust aerosol load in the atmosphere during local noon (Legrand et al., 2001; Deepshikha et al., 2006a, b). Here, we have used a modified approach to retrieve dust index during night since assessment of diurnal 
(a) Reference Image ( $\left(1^{\text {st }}-15^{\text {th }}\right)$ Jan 2003

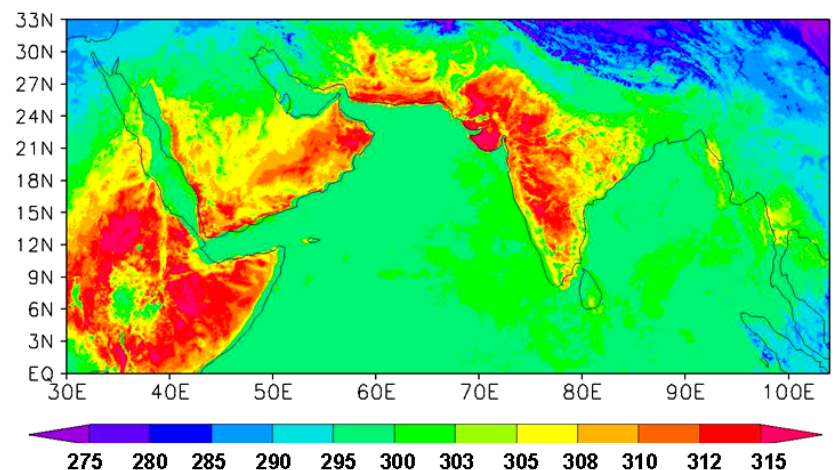

(b) Difference Image $1^{\text {st }}$ Jan 2003

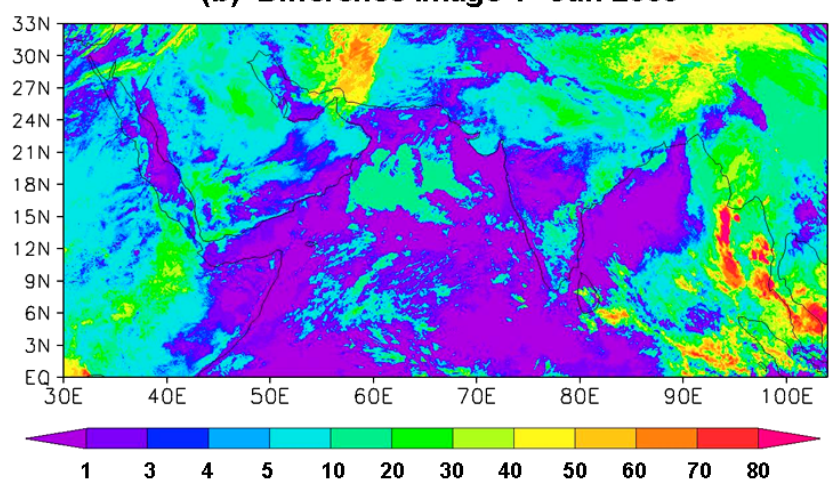

Fig. 1. An example of (a) reference image (1-15 January 2003) and (b) difference image for 1 January 2003.

average infrared forcing essentially requires information on dust aerosols during night. In this paper, infrared radiance $(10.5-12.5 \mu \mathrm{m})$ from the METEOSAT-5 satellite (of European Space Agency, ESA) has been used (5-km resolution) to retrieve dust aerosol characteristics. During the Indian Ocean Experiment (INDOEX), METEOSAT-5 was moved to $66^{\circ} \mathrm{E}$ and provided an excellent opportunity to study dust aerosols over India and adjacent continents.

\section{Data and analysis}

Satellite measured infrared (IR) radiance acquired from METEOSAT-5 in the 10.5 to $12.5 \mu \mathrm{m}$ wavelength band (at $\sim 5 \mathrm{~km}$ resolution) was used to retrieve dust aerosol properties. An (IR brightness temperature) IRBT depression, caused by the presence of dust aerosols in the atmosphere, can be used as an index of dust load and is called infrared difference dust index (IDDI) (Tanr'e and Legrand, 1991; Legrand et al., 2001). Details of the this approach is available in the literature and are not repeated here (see Legrand et al., 2001; Deepshikha et al., 2006a, b). However, a brief description is provided below. The IDDI images were created using radiometric counts (RC) from METEOSAT-5. Radiometric counts are first converted into radiance using cali- bration coefficients. Radiance data is converted into brightness temperature (IRBT) data, using an inverse Planck Function. This IRBT forms the original image. An "original image" contains all the radiative information about surface and atmosphere (Legrand et al., 2001). The next step was to create a "reference image" representing clear-sky conditions for consecutive, non-overlapping periods, whose duration is short enough to eliminate the seasonal effects but long enough to ensure that the clear-sky or near clear-sky conditions exist for at least one measurement, for each pixel. The purpose of the "reference image" is to separate the land effect from the "original image". A 15-day reference period is used here. For a given pixel, the maximum in the daily values of IRBT within a given reference period is assumed to represent the characteristics of the target pixel, as in cloudfree and dust free (background) conditions (an example is shown in Fig. 1a). Next, a "difference image", exhibiting the clouds and dust patterns separated from the permanent surface features, was obtained by subtracting the individual day "original image" (or IRBT) from the "reference image" for that period. The "difference image" shows only the variable atmospheric radiative effects related to both clouds and dust. Difference values represent the reduction in IRBT due to dust aerosols, provided that cloudy pixels are identified and screened (an example is shown in Fig. 1b). Cloudy pixels were screened using the spatial coherence method (Coackley and Bretherton, 1982). Now the resulting image after cloud screening is an IDDI image, which represents the regional distribution of dust aerosols. The METEOSAT-5 IR radiance data were analyzed for all days during 2003.

The METEOSAT provides infrared radiance data every half an hour, covering day and night. However, we note that the IDDI algorithm, valid for daytime, will no longer hold during the night because dust is then hotter than the theoretical dust-free reference, while clouds are colder as also acknowledged in Deepshikha et al. (2006b). Hence for nighttime retrieval of dust, we have followed a modified approach by re-ordering the steps as follows (a) Follow the daytime IDDI algorithm: create "reference image" representing the hottest pixels; (b) create "difference image" and then use it for cloud identification and masking; (c) apply the cloud mask to the original IRBT images; (d) apply the IDDI algorithm again, but with the "minimum reference". It may be noted that while using the "minimum" reference method for retrieval of IDDI during the night, IDDI is negative and in this case the absolute magnitude of IDDI is a measure of dust load.

\section{Results and discussion}

An example of IDDI image over the Indian "Thar" desert is shown in Fig. 2a for 4 March 2003. Corresponding image for night is also shown (Fig. 2b). The METEOSAT IR radiance data were analyzed for all days (at three hour 
04 March 2003: Noon
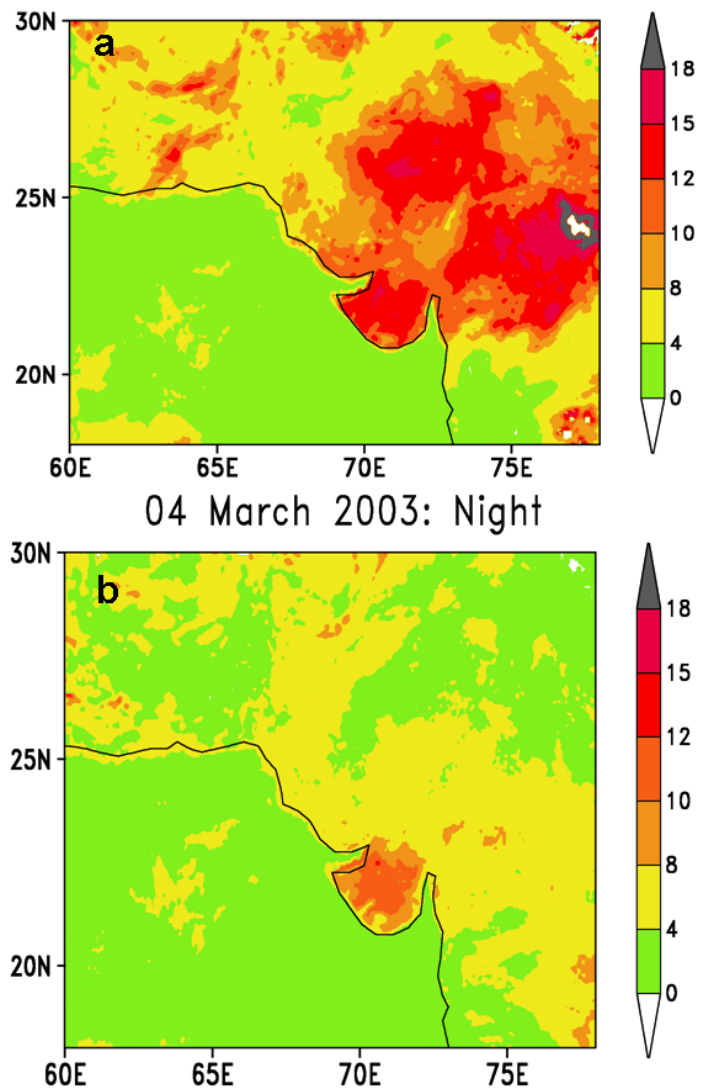

Fig. 2. (a) An example of IDDI image over the Indian "Thar" desert 4 March 2003. (b) Corresponding image for night of same day.

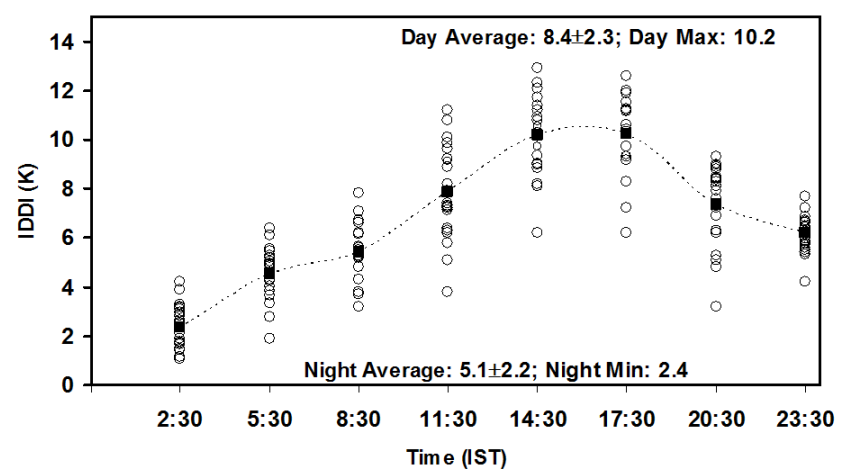

Fig. 3. Diurnal variation of IDDI observed over "Thar" desert in India for May 2003. Mean value is shown as solid squares connected by dotted line.

intervals) during 2003 to study the day-night differences in IDDI, which revealed that there exists significant diurnal variation in the dust. Diurnal variation of IDDI observed over "Thar" desert in India is shown in Fig. 3 for May 2003. A detailed analysis in this regard suggests that the maximum dust load occurs during the daytime in the after noon hours.
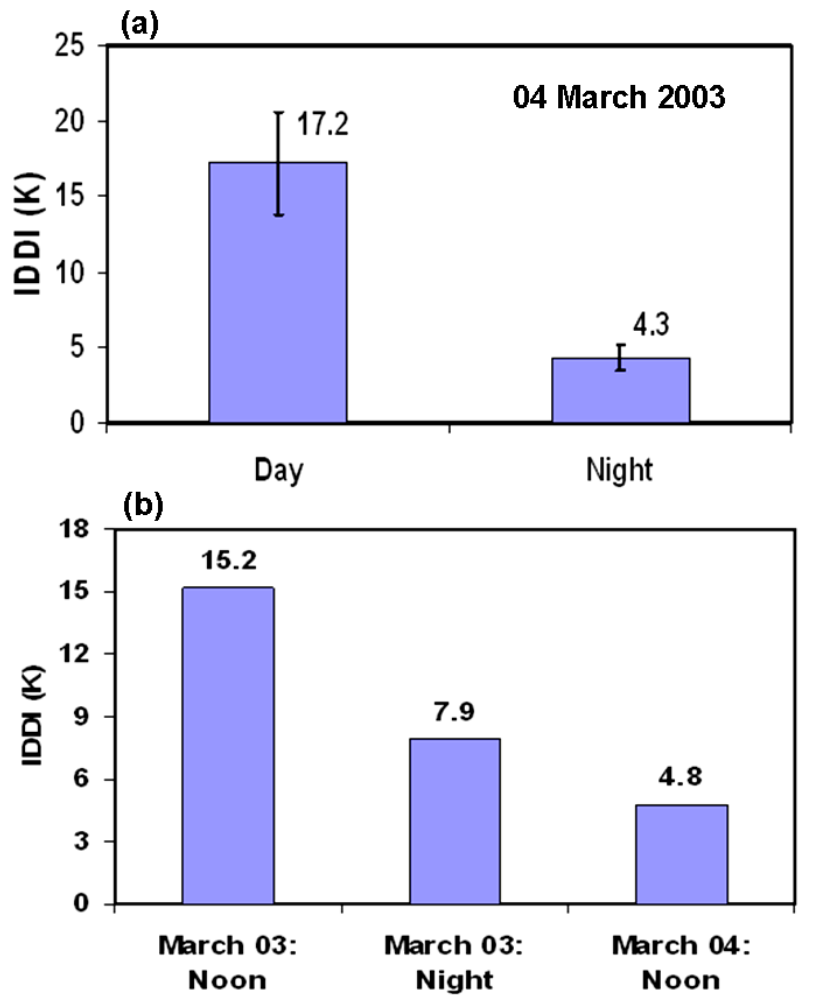

Fig. 4. Day-night differences in IDDI (a) for Indian desert (22$28 \mathrm{~N} ; 67-77 \mathrm{E})$ and (b) for Saudi Arabian desert (15-25 N; 42$55 \mathrm{E})$.

The maximum change in IDDI is as much as a factor of three to four between day and night and factor of two variations are commonly observed. Day-to-night differences in IDDI observed over desert in India (Fig. 4a) and Saudi Arabia (Fig. 4b) shows IDDI variations from 17.2 to 4.3 in a matter of a few hours. Annual mean (for 2003) day-night difference in IDDI is estimated as high as a factor of 2.2. This observation has consequent impact on long-wave dust radiative forcing. During daytime, when surface temperature is maximum dust load is also maximum while at night surface temperature decreases, as well as the dust load. This indicates that neglecting the diurnal variation in dust loading can lead to errors in the estimation of long-wave radiative forcing.

To study this effect, sensitivity studies have been carried out. To describe a wide range of possible aerosol compositions, Hess et al. (1998) modelled aerosols as various components, each of them meant to be representative of a certain origin. The components can be combined to form various aerosol mixtures. These models are developed based on comprehensive data over a large number of locations. Here, we used dust optical properties from Hess et al. (1998) and incorporated them in the Santa Barbara DISORT Atmospheric Radiative Transfer (SBDART) model (Ricchiazzi et al., 1998) to estimate the dust aerosol impact on long wave (LW) radiative fluxes. Using data on dust properties, we have modeled 
(a) Long Wave Forcing $\left(\mathrm{W} \mathrm{m}^{-2}\right)$ : January 2003

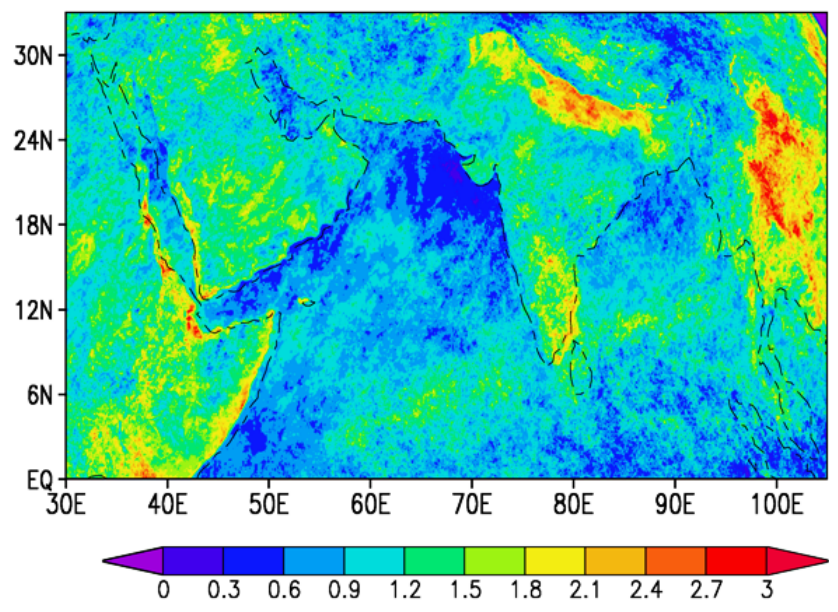

(b) Long Wave Forcing (W m-2): May 2003

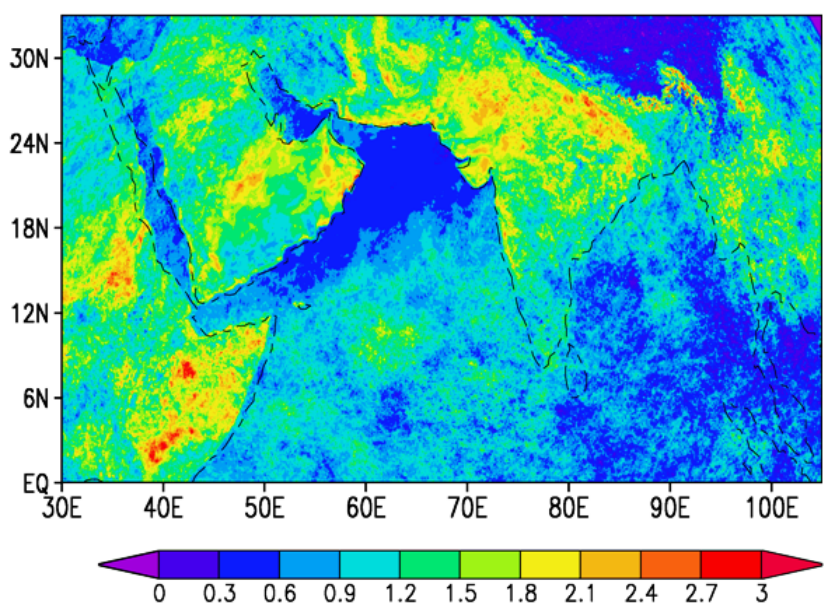

Fig. 5. Regional distribution of long wave dust forcing of over Afro-Asian region (0-35 N; 30 E-100 E) for (a) January 2003 and (b) May 2003.

the IDDI as a function of change in long wave fluxes. The refractive indices used are wavelength-dependent. The approach here is to simulate infrared radiance depression for various dust loadings in terms of IDDI. Thus, using radiative transfer simulations, we have estimated long wave dust radiative forcing for given IDDI values, which enabled construction of maps of dust forcing from maps of IDDI. Conventional method is to assume day time dust loading for night and hence for estimating diurnally averaged forcing. Here, we have accounted the diurnal variation of dust (in terms of IDDI), thus arrived at an improved estimate of long dust forcing over Afro-Asian region. Regional distribution of long wave dust forcing is shown in Fig. 5. During the dry season over source regions long-wave radiative forcing at the top of the atmosphere (TOA) was as high as +6 to $8 \mathrm{~W} \mathrm{~m}^{-2}$. The regionally $(0-35 \mathrm{~N} ; 30 \mathrm{E}-100 \mathrm{E})$ and annually averaged longwave dust radiative forcing was $+2.6 \pm 1.8 \mathrm{~W} \mathrm{~m}^{-2}$. This is lower than the value of $+3.4 \pm 1.6 \mathrm{~W} \mathrm{~m}^{-2}$ reported by Deepshikha et al. (2006b) without considering the diurnal variation of dust loading. Liao and Seinfeld (1998) estimated global mean clear-sky, long-wave radiative forcing at TOA in the range of +0.2 to $+1.0 \mathrm{~W} \mathrm{~m}^{-2}$. Similar results were reported by Tegen and Lacis (1996) and Tegen et al. (1997). The long wave aerosol forcing reported in this study for the Afro-Asian regions are several factors higher than the values reported for global average.

\section{Conclusions}

We have used a modified approach to retrieve dust index during night since assessment of diurnal average infrared dust forcing essentially requires information on dust aerosols during night. Infrared radiance $(10.5-12.5 \mu \mathrm{m})$ acquired from the METEOSAT- 5 satellite ( $\sim 5 \mathrm{~km}$ resolution) is used here. Major conclusions from this study are listed below.

1. We found that the infrared "dust index" algorithm, valid for daytime, will no longer hold during the night because dust is then hotter than the theoretical dust-free reference.

2. A detailed analysis suggests that the maximum dust load occurs during the daytime. Over the desert regions of India and Africa, maximum change in dust load is as much as a factor of four between day and night and factor of two variations are commonly observed.

3. We found that utilizing day time data for estimating the diurnally averaged long-wave dust radiative forcing results in significant errors (as much as 50 to $70 \%$ ).

4. Annually and regionally averaged long wave dust radiative forcing at the top of the atmosphere over AfroAsian region is $2.6 \pm 1.8 \mathrm{~W} \mathrm{~m}^{-2}$, which is 30 to $50 \%$ lower than those reported earlier.

5. Our studies indicate that neglecting diurnal variation of dust while assessing its radiative impact leads to an overestimation of dust radiative forcing, which in turn result in underestimation of the radiative forcing of anthropogenic aerosols.

Acknowledgements. Authors thank EUMETSAT for providing METEOSAT-5 data. One of the authors (SD) thank Department of Science and Technology, New Delhi for supporting this work as part of Woman Scientist Scheme (WOS-A) Grant No: SR/WOSA/AS-08/2006).

Topical Editor P. M. Ruti thanks one anonymous referee for her/his help in evaluating this paper. 


\section{References}

Chandra, S., Satheesh, S. K., and Srinivasan, J.: Can the state of mixing of black carbon aerosols explain the mystery of "excess" atmospheric absorption?, Geophys. Res. Lett., 31, L19109, doi:10.1029/2004GL020662, 2004.

Coackley, J. A. and Bretherton, F. P.: Cloud cover from high resolution scanner data: method and preliminary results, J. Geophys. Res., 87, 4917-4932, 1982.

Deepshikha, S., Satheesh, S. K., and Srinivasan, J.: Regional Distribution of Absorbing Efficiency of Dust Aerosols over India and Adjacent Continents inferred using Satellite Remote Sensing, Geophys. Res. Lett., 32(3), L03811, doi:10.1029/2004GL022091, 2005.

Deepshikha, S., Satheesh, S. K., and Srinivasan, J.: Dust aerosols over India and adjacent continents retrieved using METEOSAT infrared radiance Part I: sources and regional distribution, Ann. Geophys., 24, 37-61, doi:10.5194/angeo-24-37-2006, 2006 a.

Deepshikha, S., Satheesh, S. K., and Srinivasan, J.: Dust aerosols over India and adjacent continents retrieved using METEOSAT infrared radiance Part II: quantification of wind dependence and estimation of radiative forcing, Ann. Geophys., 24, 63-79, doi:10.5194/angeo-24-63-2006, 2006b.

Haywood, J. and Boucher, O.: Estimates of the direct and indirect radiative forcing due to tropospheric aerosols: A review, Rev. Geophys., 38(4), 513-543, 2000.

Hess, M., Koepke, P., and Schult, I.: Optical properties of aerosols and clouds: The software package OPAC, B. Am. Meteorol. Soc., 79, 831-844, 1998.

Intergovernmental Panel on Climate Change (IPCC): Fourth Assessment Report, Cambridge University Press, 2007.
Kaufman, Y. J., Tanré, D., Gordon, H. R., et al.: Passive remote sensing of tropospheric aerosol and atmospheric correction for the aerosol effect, J. Geophys. Res., 102(D14), 16815-16830, 1997.

Legrand, M., Plana-Fattori, A., and N'doume, C.: Satellite detection of dust using the IR imagery of Meteosat 1 . Infrared Difference Dust Index, J. Geophys. Res., 106(D16), 18251-18274, 2001.

Liao, H. and Seinfeld, J. H.: Radiative forcing by mineral dust aerosols: sensitivity to key variables, J. Geophys. Res., 103, 31637-31645, 1998.

Ricchiazzi, P., Yang, S., Gautier, C., and Sowle, D.: SBDART, A research and teaching tool for plane-parellel radiative transfer in the Earth's atmosphere, B. Am. Meteorol. Soc., 79, 2101-2114, 1998.

Seinfeld, J. H., Carmichael, G. R., Arimoto, R., et al.: Regional Climatic and Atmospheric Chemical Effects of Asian Dust and Pollution, B. Am. Meteorol. Soc., 367-380, 2004.

Sokolik, I. N., Toon, O. B., and Bergstrom, R. W.: Modeling the radiative characteristics of airborne mineral aerosols at infrared wavelengths, J. Geophys. Res., 103(D8), 8813-8826, 1998.

Tanré, D. and Legrand, M.: On the satellite retrieval of Saharan dust optical thickness over land: Two different approaches, J. Geophys. Res., 96, 5221-5227, 1991.

Tegen, I. and Lacis, A. A.: Modeling of particle size distribution and its influence on the radiative properties of mineral dust aerosol, J. Geophys. Res.-A., 101(D14), 19237-19244, 1996.

Tegen, I., Hollrig, P., Chin, M., et al.: Contribution of different aerosol species to the global aerosol extinction optical thickness: Estimates from model results, J. Geophys. Res.-A., 102(D20), 23895-23915, 1997. 